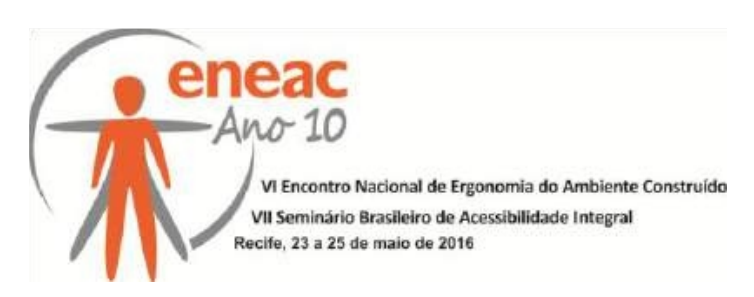

\title{
ACESSIBILIDADE EM EDIFÍCIOS PÚBLICOS: ESTUDO DE CASO - INSTITUTO DE EDUCAÇÃO FÍSICA E ESPORTES NO CAMPUS DO $\mathrm{PICl}$ - UFC
}

\author{
DO NASCIMENTO, Raquel Martins (1); \\ SALES, Fernanda Rocha (2); \\ SANTIAGO, Zilsa Maria Pinto (3)
}

(1) Universidade Federal do Ceará, Graduada

e-mail: raquelmartins.arq.urb@gmail.com

(2) Universidade Federal do Ceará, Graduanda

email: fernanda roxa@hotmail.com

(3) Universidade Federal do Ceará, Doutora

e-mail: zilsa@arquitetura.ufc.br

\begin{abstract}
RESUMO
Reconhecendo a importância da acessibilidade espacial e o potencial inclusivo da prática de esportes, este trabalho tem o objetivo de contribuir com o debate sobre o processo de adequação de prédios públicos, sendo escolhido para análise o Instituto de Educação Física e Esportes (IEFES) da Universidade Federal do Ceará (UFC), dada a importância do complexo como equipamento público de ensino superior e portal de inclusão, onde funcionam o curso de Educação Física e programas esportivos de cunho social, inclusive para pessoas com deficiência. Apresenta, portanto, os resultados de análise das condições de acessibilidade do prédio do referido instituto de ensino superior, tendo como referencial metodológico técnicas de Avaliação Pós-Ocupação (APO).
\end{abstract}

Palavras chave: Acessibilidade; Avaliação Pós-Ocupação; Instituição Pública de Ensino Superior.

\begin{abstract}
Recognizing the importance of accessibility and inclusive space of sports, this work has the objective of contributing to the debate on the adequation process of public buildings, being chosen for analysis the Institute of Physical Education and Sports (IEFES) at Federal University of Ceará (UFC), given the importance of the complex as public higher education equipment and include portal, where the Physical Education course and social sports programs works, including for people with disabilities. This paper presents the analysis results of the physical accessibility's conditions of a higher education public institution, using the technical methodology of Post-Occupancy Evaluation (POE).
\end{abstract}

Keywords: Accessibility, Post-Occupancy Evaluation, Public Institution of Higher Education. 


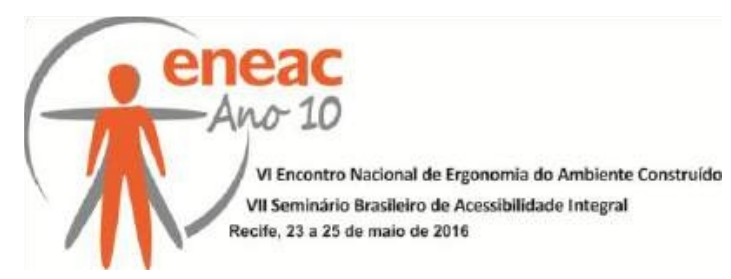

\section{INTRODUÇÃO}

A acessibilidade é uma questão de direito e de atitudes, aspectos intrinsecamente relacionados entre si. Como direito, tem sido conquistada gradualmente ao longo da história social; como atitude, no entanto, depende de uma gradual mudança nas crenças, valores, significados, atitudes e comportamentos para com a pessoa com deficiência na sociedade. Não é uma condição apenas favorável, mas obrigatória: trata-se de um direito fundamental e universal de qualquer cidadão em ter acesso a espaços, informações e serviços. Aproximando-se do tema multidisciplinar, concentramo-nos na contribuição principal que um profissional da Arquitetura pode oferecer na produção espacial.

Segundo o Decreto 5.296/2004 para regulamentar a Lei 10.048/2000, traz a definição de acessibilidade como:

condição para utilização, com segurança e autonomia, total ou assistida, dos espaços, mobiliários e equipamentos urbanos, das edificações, dos serviços de transporte e dos dispositivos, sistemas e meios de comunicação e informação, por pessoa portadora de deficiência ou com mobilidade reduzida.( BRASIL. Decreto No 5.296, 2004).

Esta condição deve ser incorporada desde a concepção de projetos, em grau de relevância e importância tão elevada quanto seu sentido mais óbvio. Projetar espaços para a utilização de pessoas se faz necessário ampliar o conceito de acessibilidade para a sua plenitude e caráter universal: o usuário não se encerra no "modulor" corbusiano ou no homem vitruviano: o usuário é um ser humano tão variado quanto a espécie permite. Pessoas com algum tipo de deficiência já representam hoje $24 \%$ da população no país, ou seja, um em cada quatro brasileiros (Censo 2010, IBGE). A padronização de elementos arquitetônicos e a insensibilidade de projetistas, apesar do histórico, continuam a contribuir para a formação de barreiras.

A relevância da acessibilidade espacial é reforçada por lei em espaços públicos e coletivos. No caso de instituições públicas de ensino, o não cumprimento desses direitos pode restringir seu potencial inclusivo, já que as barreiras físicas e sociais podem impedir os estudos de pessoas com deficiência ou com mobilidade reduzida. Além de profissionais qualificados, essa instituição precisa formar cidadãos e possuir um ambiente que atenda as normas de acessibilidade e estudos de desenho universal é uma lição de inclusão para todos que utilizam esse espaço.

Reconhecendo a importância do desenho universal em edifícios dessa tipologia, o Grupo de Pesquisa do Departamento de Arquitetura e Urbanismo da Universidade Federal do Ceará UFC em colaboração com a Secretaria de Acessibilidade da Instituição selecionaram para estudo de caso, o Instituto de Educação Física e Esportes (IEFES), localizado no Campus do Pici/UFC, onde funciona o curso de Educação Física. O objetivo deste artigo é, portanto, contribuir com o debate da acessibilidade espacial em instituições públicas de ensino superior relatando os resultados da análise das condições de acessibilidade do complexo arquitetônico do IEFES, confrontando a realidade com as exigências das normas e decretos brasileiros, além das demandas apontadas por usuários do local.

\section{METODOLOGIA}

Como metodologia básica para pesquisa de campo, foram adotadas as técnicas da Avaliação Pós-Ocupação (APO) que vêm sendo aplicadas sistematicamente em vários países como EUA, França e também no Brasil. O termo Avaliação Pós-Ocupação (APO), 


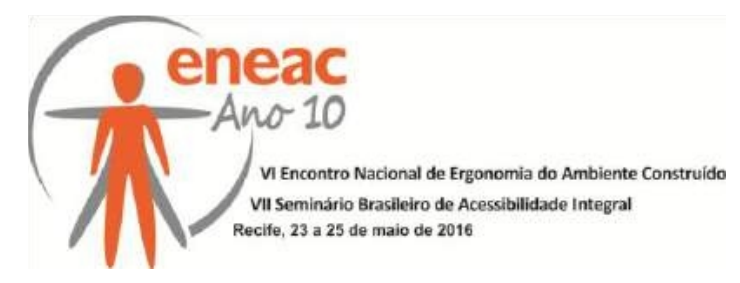

segundo Preiser (1988) é o processo de coleta sistemática de dados, análise, e comparação com critérios de performance explicitamente declarados que pertencem a ambientes construídos e ocupados.

De acordo com Ornstein (1992), essa metodologia pretende diagnosticar aspectos positivos e negativos da edificação, a partir da avaliação de fatores técnicos, funcionais, econômicos e comportamentais do ambiente em uso, considerando a opinião de técnicos, projetistas e usuários. Quando são encontrados aspectos negativos, definem-se recomendações que minimizem, ou até mesmo corrijam os problemas detectados, além de se utilizar os resultados dessas avaliações sistemáticas (estudos de caso) para realimentar o ciclo do processo de produção e uso de ambientes semelhantes, buscando aperfeiçoar o desenvolvimento de projetos futuros. Para análise das condições de acessibilidade físicas, foi realizada uma APO sobre o objeto de estudo. Ainda sobre o método, Cambiaghi explica:

\begin{abstract}
A APO estuda edifícios e demais ambientes construídos quanto à satisfação do usuário e também do ponto de vista do especialista. Essa avaliação deve ser feita durante o processo de utilização (...). Em síntese, a APO é um instrumento de referência que avalia as questões relativas à acessibilidade. (CAMBIAGHI, 2007, pp 160-161).
\end{abstract}

Destaca-se no levantamento de dados para esta metodologia a consideração da relação do objeto com o contexto urbano e a conexão entre as edificações, avaliando percursos e materiais de pavimentação e acabamento que influenciem na fluidez dos deslocamentos. Foi aplicado o procedimento da Avaliação Física dos edifícios, parte dos procedimentos da APO, constando de visitas exploratórias e da realização de um percurso em todos os edifícios que compõem o instituto. A metodologia de campo também considera a técnica de "walk-through", método de análise que possibilita a identificação de aspectos positivos e negativos do edifício, consistindo em percorrer todo o edifício, preferencialmente munido de plantas ou acompanhado do projetista ou de usuários, de modo que se possa formular perguntas com o objetivo de conhecer melhor o edifício, sua construção e as atuais funções de cada ambiente, como é utilizado por seus usuários. (PREISER, 1988).

Nesta pesquisa, em específico, foram realizadas visitas ao IEFES em dezembro de 2013, quando foram coletados relatos de usuários e instrutores do local, realizadas anotações com base em cheklist e levantamento fotográfico, sendo produzido um relatório de vistoria técnica. As impressões e realidade observadas no complexo de edificações escolhido foram confrontadas com as diretrizes do Decreto 5.296/2004, com as recomendações da NBR 9050/2004 e do Guia de Acessibilidade - Ceará (2009).

\title{
3. CARACTERIZAÇÃO DO OBJETO DE ESTUDO
}

O Campus do Pici é o maior campus da Universidade Federal do Ceará. Está localizado no bairro de mesmo nome, inserido na Secretaria Regional III, onde estão os bairros da porção oeste da cidade. O IEFES localiza-se na porção sul do campus, próximo ao acesso que se dá pela Rua Pernambuco. Essa rua possui circulação de transporte coletivo, porém a variedade de ônibus não é grande por se tratar de uma via local (Etufor, 2013).

Outra forma de acessar o Instituto por transporte público pode ser feito por meio da Avenida Humberto Monte, que é o acesso mais conhecido do campus e por onde passam várias linhas diferentes de ônibus e transporte alternativo. Porém, essa entrada se localizada no extremo oposto aos blocos do IEFES, sendo necessária a utilização do transporte interno oferecido pela Universidade (vide figura 1).

A origem do IEFES data de 1975, no já citado campus. Funcionou inicialmente através da Coordenadoria de Educação Física e Desporto (CEFEL). O curso de Educação Física surge 


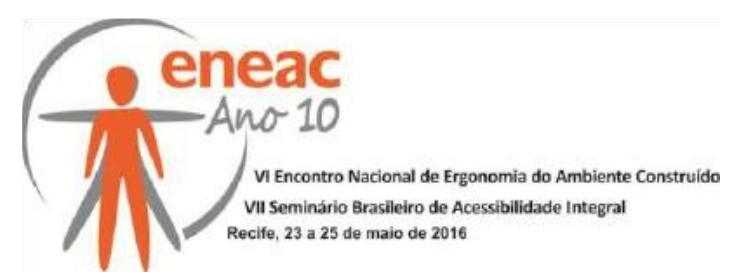

em 1992, como uma iniciativa conjunta entre os professores da CEFEL e da Faculdade de Educação (Faced). Com a consolidação do campo da Educação Física, foi criado em 1993 o IEFES como um Instituto plural de ensino, pesquisa e extensão. Desde a criação até 2009, o curso de Educação Física funcionou na Faced, no bairro Benfica, cujo espaço era insuficiente e inadequado para as várias atividades esportivas, ou seja, o curso sofreu, durante aqueles anos, com a inadequabilidade da estrutura física para a efetivação do processo de ensino, principalmente no que diz respeito às disciplinas que necessitavam de espaço físico específico.

Figura 1 - Localização do Campus do Pici e IEFES

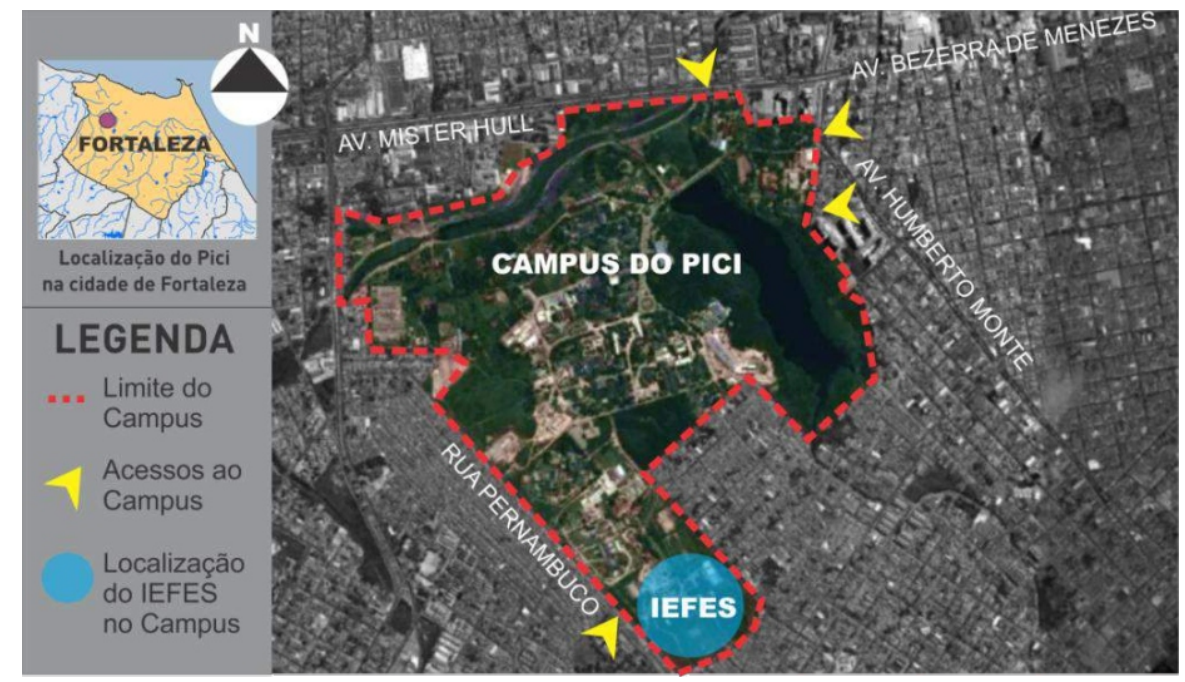

Fonte: Autoras com base gráfica do Google Earth (2014).

Uma vez que a disciplina de Educação Física, que era geral para todos os cursos, deixou de ser obrigatória, a utilização da área esportiva da UFC havia ficado com uma manutenção menos constante, e assim foi se deteriorando. Foi quando foi aprovada, em 2009, a mudança da sede do curso para o campus do Pici, onde foram feitas reformas e criadas novas instalações para atenderem as necessidades do novo programa. A coordenação do IEFES, em decorrência do Plano de Reestruturação e Expansão das Universidades Federais (REUNI), apontou também para a ampliação do quadro de professores efetivos, a ampliação da oferta de novas vagas e a criação do curso noturno, além da condição de desenvolvimento de projetos para a comunidade da UFC e população do entorno. Dentre os projetos de extensão utilizados pelo público interessado nos equipamentos do Instituto, existem alguns que têm foco nas pessoas com deficiência e mobilidade reduzida, como é o caso do Projeto Esporte Paraolímpico e Aprendizagem Motora, que foi visitado pela equipe de pesquisa.

O IEFES possui aproximadamente 20,26 hectares de área, sendo sua atual estrutura física constituída de blocos didáticos, parque aquático, pista de atletismo, ginásio coberto, 


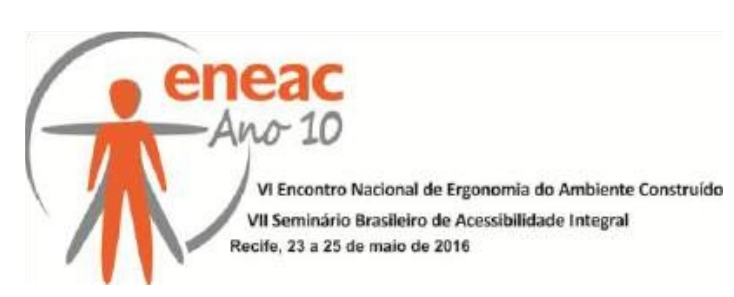

banheiros e vestiários, cantina, áreas de convivência, estacionamento, campo de futebol, salas multiuso e laboratórios, além de edificações administrativas.

\section{ANÁLISE E RESULTADOS}

Como já foram citadas, na metodologia, as visitas ao local seguiram um roteiro prévio, organizado tendo em vista os vários setores do complexo de ensino, a saber: parque aquático, área de recreação, cantina e pista de corrida; bloco administrativo; bloco didático e ginásio coberto.

\subsection{Acessos e Parque Aquático}

A entrada principal para o complexo edificado, que concentra o setor administrativo e permite a distribuição para as diversas áreas educativas do IEFES, apresenta vagas reservadas para pessoas com deficiência. A rampa de entrada, porém, que acompanha o talude existente no terreno, está fora dos padrões indicados na NBR 9050/2004, com inclinação elevada, superior à máxima exigida de $8,33 \%$. A altura do corrimão apresenta uma pequena diferença na altura (apresentando $90 \mathrm{~cm}$ de altura, e não os $92 \mathrm{~cm}$ definidos pela norma) e não foi executada a barra inferior do corrimão, fato enfatizado pelo instrutor que acompanhou a visita, que a falta deste elemento representa uma dificuldade para os usuários de cadeira de rodas, principalmente por ser a única rampa de acesso ao complexo edificado (vide figura 2).

Figura 2 - Rampa de acesso principal ao bloco administrativo do IEFES

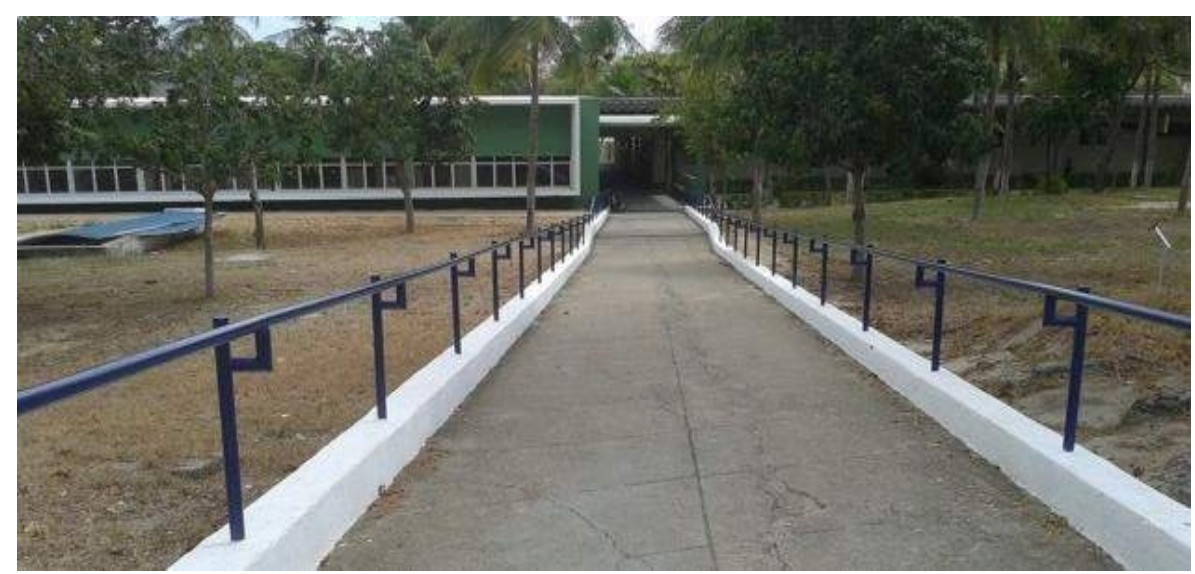

Fonte: Acervo pessoal (2013).

Os problemas de acesso são recorrentes: foi identificada falta de integração das partes pela ausência de rampas adequadas à norma e passagens de nível com pavimentação adequada. Algumas edificações foram consideradas inacessíveis, como a área de recreação coberta (vide figura 3) que além de apresentar como revestimento de piso o bloco de concreto vazado intertravado, apresenta grandes desníveis no acesso. 


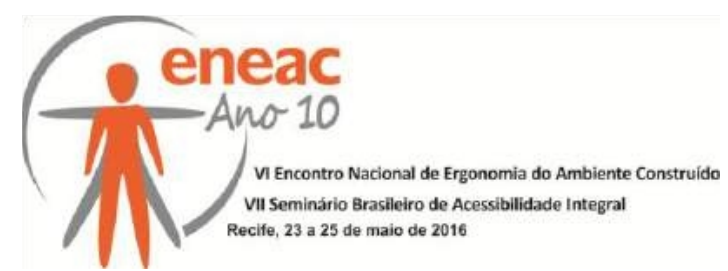

Figura 3 - Acesso à área recreativa

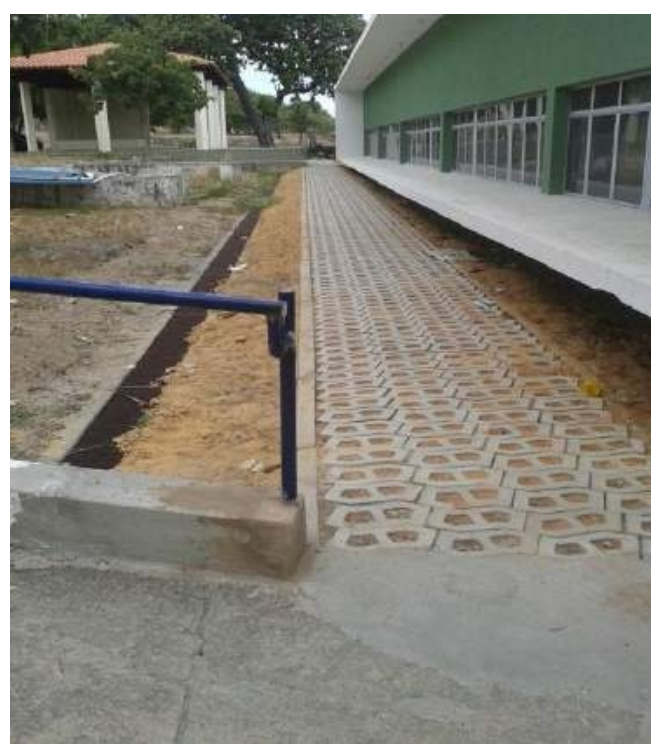

Fonte: acervo pessoal 2013
Figura 4a e 4b - Acesso à cantina

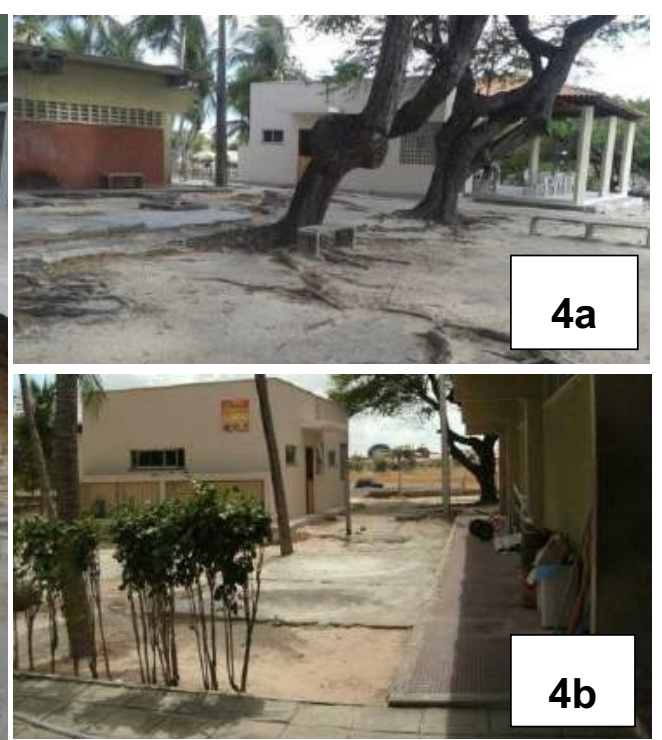

Fonte: acervo pessoal 2013

Figura 5a e 5b - Bancadas e desníveis da cantina

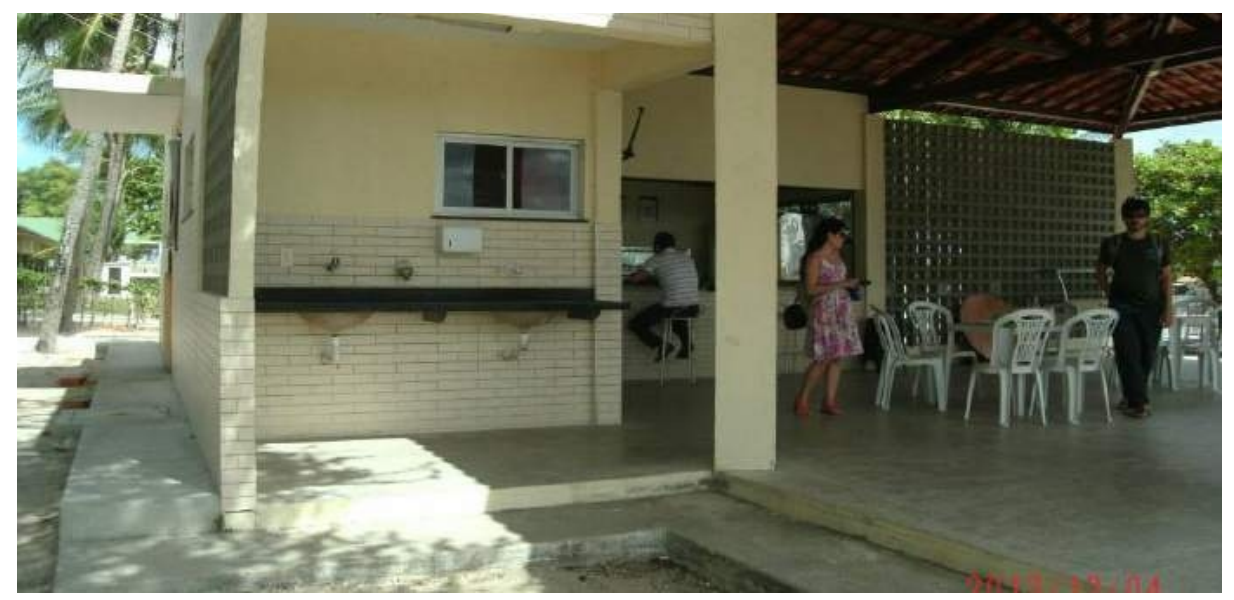

Fonte: Acervo pessoal (2013).

Outros espaços e equipamentos apresentam soluções inadequadas de acessibilidade. Dentre estes, constam: a pista de corrida, com acesso de rampa por um pátio com pavimentação irregular e com inclinação aproximada de $25 \%$ sem corrimão duplo nem sinalização (vide figura 6); e a área da piscina. 


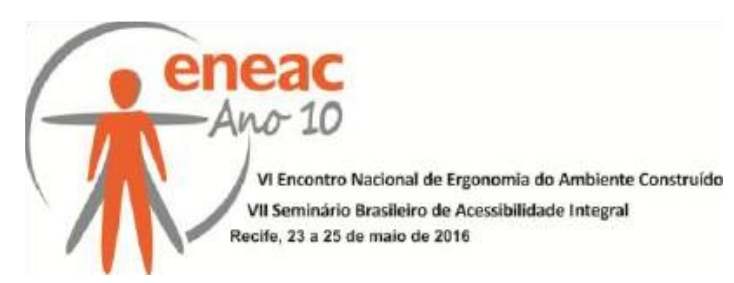

Figura 6 - Rampa de acesso à pista de corrida

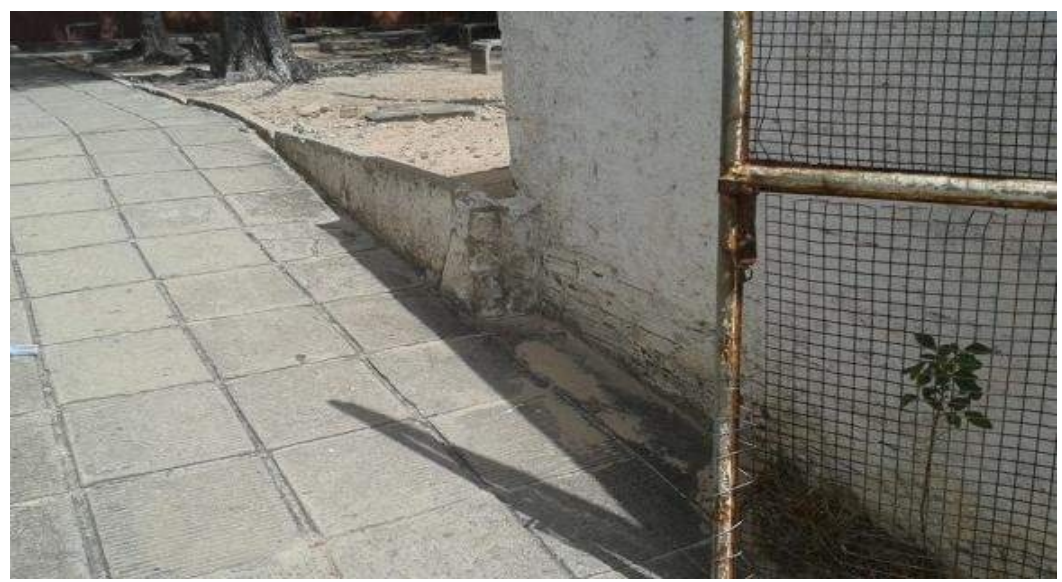

Fonte: Acervo pessoal (2013).

O acesso à piscina feito pelo paratleta que acompanhou a equipe, mostra a dificuldade de circulação, com pavimentação irregular e vários desníveis, vencidos por pequenas rampas de inclinação de $28 \%$. A rampa final de acesso à piscina também é muito inclinada, com aproximadamente $25,5 \%$, e quase não possui distanciamento em relação ao gradil da piscina, potencializando acidentes (vide figura 7).

Além do acesso dificultado, a área de ducha se encontra com desnível e sem rampa. A transposição do deck para piscina se faz somente pela escada vertical, o que, segundo instrutor, causa constrangimento à pessoa com deficiência, sem autonomia total nem parcial. Dada a alta utilização da piscina por usuários de cadeira de rodas, é recomendável a execução de um elemento de transposição ou instalação de um equipamento mecânico de transposição vertical, como indicado no Decreto 5.296/2004.

Figura 7 - Acesso ao parque aquático 

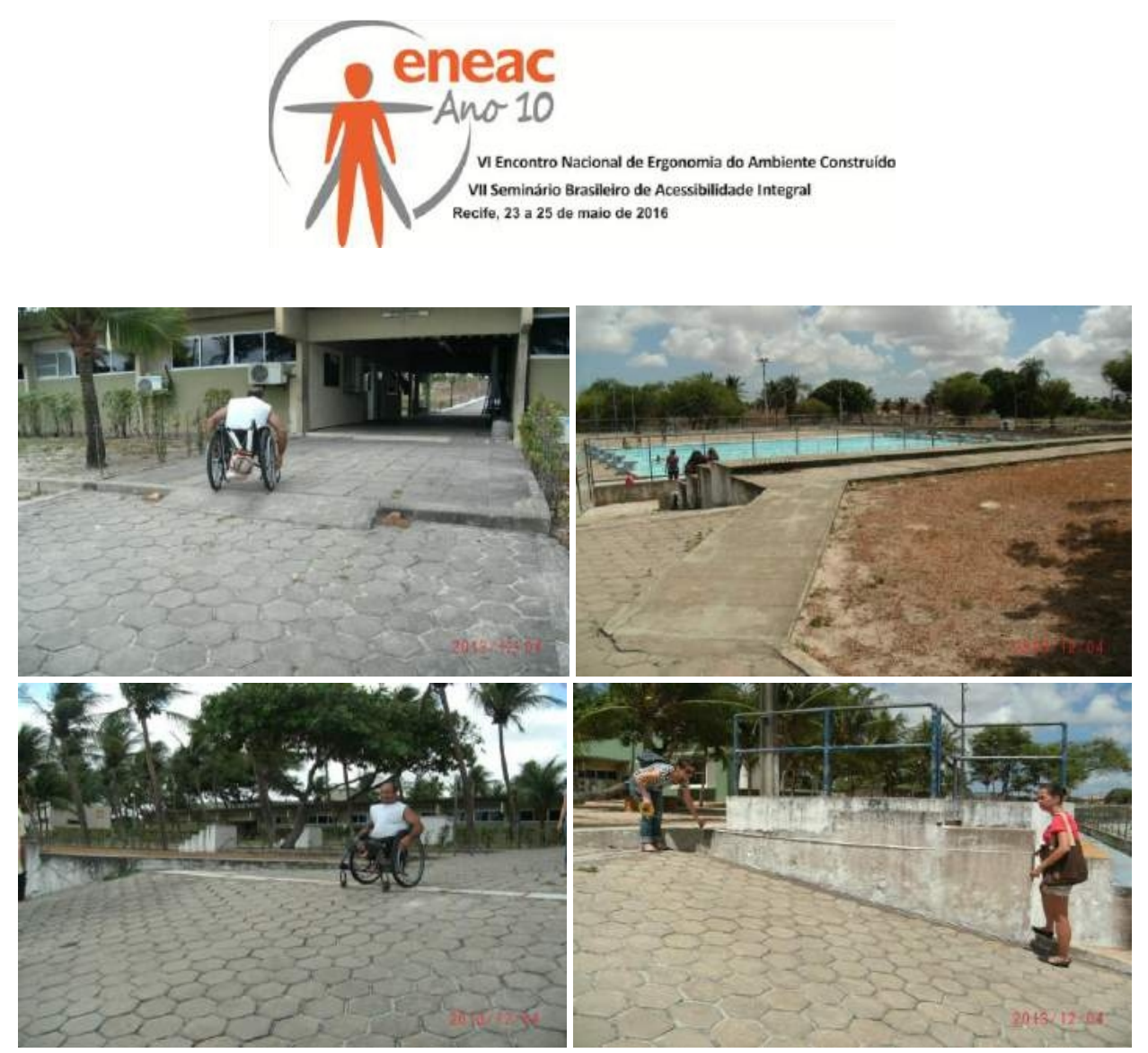

Fonte: Acervo pessoal (2013).

\subsection{Bloco Administrativo}

O bloco administrativo possui pequenos desníveis em vários pontos, inclusive no acesso às salas administrativas, além de um balcão de atendimento inadequado, com altura elevada. O banheiro, que atende aos usuários da piscina, possui um box sanitário acessível, porém, - acesso é em desnível de $3 \mathrm{~cm}$ e, considerando sua característica de vestuário, é incompleto, pois não apresenta o banco para banho e a área de transferência para área do chuveiro, ausência de algumas das barras de apoio indicadas na norma para funcionalidade deste espaço e de banco para troca de roupa (vide figura 8).

\section{Figura 8 - Secretaria e banheiro do bloco administrativo}

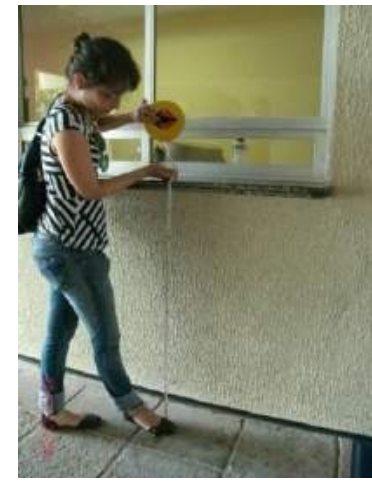

Fonte: Acervo pessoal (2013).

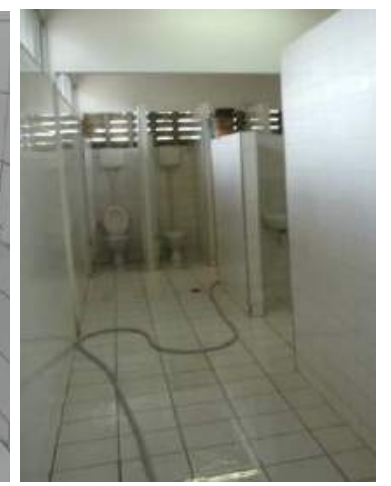

Fonte: Guia de Acessibilidade/Ceará, 2009.

\subsection{Bloco Didático}

Os blocos construídos recentemente, dentre eles, o bloco didático, e a obra da ampliação do bloco principal, com salas de aula, de professores e, inclusive academia, também 


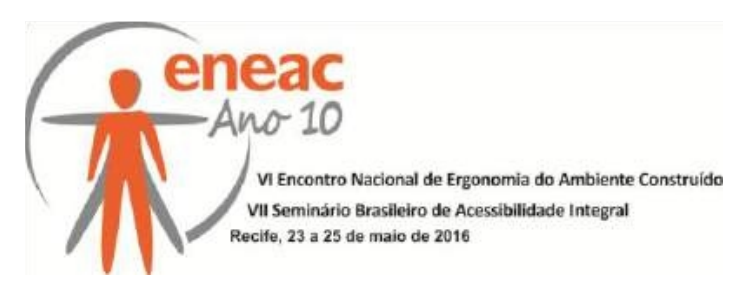

apresentam barreiras físicas. O novo bloco didático possui rampa de acesso com inclinação adequada, mas corrimão apenas de um dos lados da rampa. Internamente, há um banheiro acessível, neste caso, apenas a torneira é inadequada do tipo rosqueio. Existe um elevador hidráulico operante, embora se apresente no período da visita com defeito, não podendo ser acessado acionando-se o botão, mas apenas no andar que a máquina estiver estacionada.

A transição do bloco antigo para o novo bloco, ainda em obra, possui um desnível de $3 \mathrm{~cm}$. A circulação que possui diversos vazios com jardim ladeados por pilares de seção retangular, podem causar acidentes para pessoas com deficiência visual ou limitação cognitiva. As portas possuem largura de $80 \mathrm{~cm}$, mas não há visores ou barras para abertura. A academia, ainda em processo de acabamento, já possui instalada uma bancada de atendimento, sem área acessível (vide figura 9).

\section{Figura 9 - Bloco em obras}
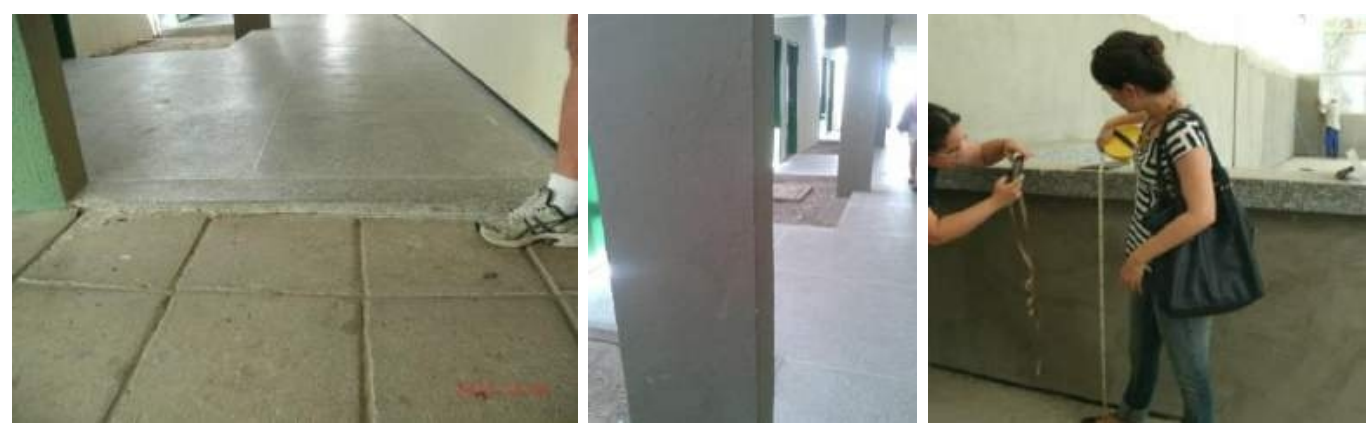

Fonte: Acervo pessoal (2013).

\subsection{Ginásio coberto}

O ginásio é uma edificação isolada no complexo do IEFES, com acesso dificultado pela ausência de pavimentação regular e em nível (vide figuras 10 e 11). O desnível de entrada para o ginásio é vencido por uma rampa inadequada às indicações da norma, sem corrimãos e inclinação superior a $20 \%$ (vide figura 12).

Figura 10 - Localização do ginásio no IEFES 

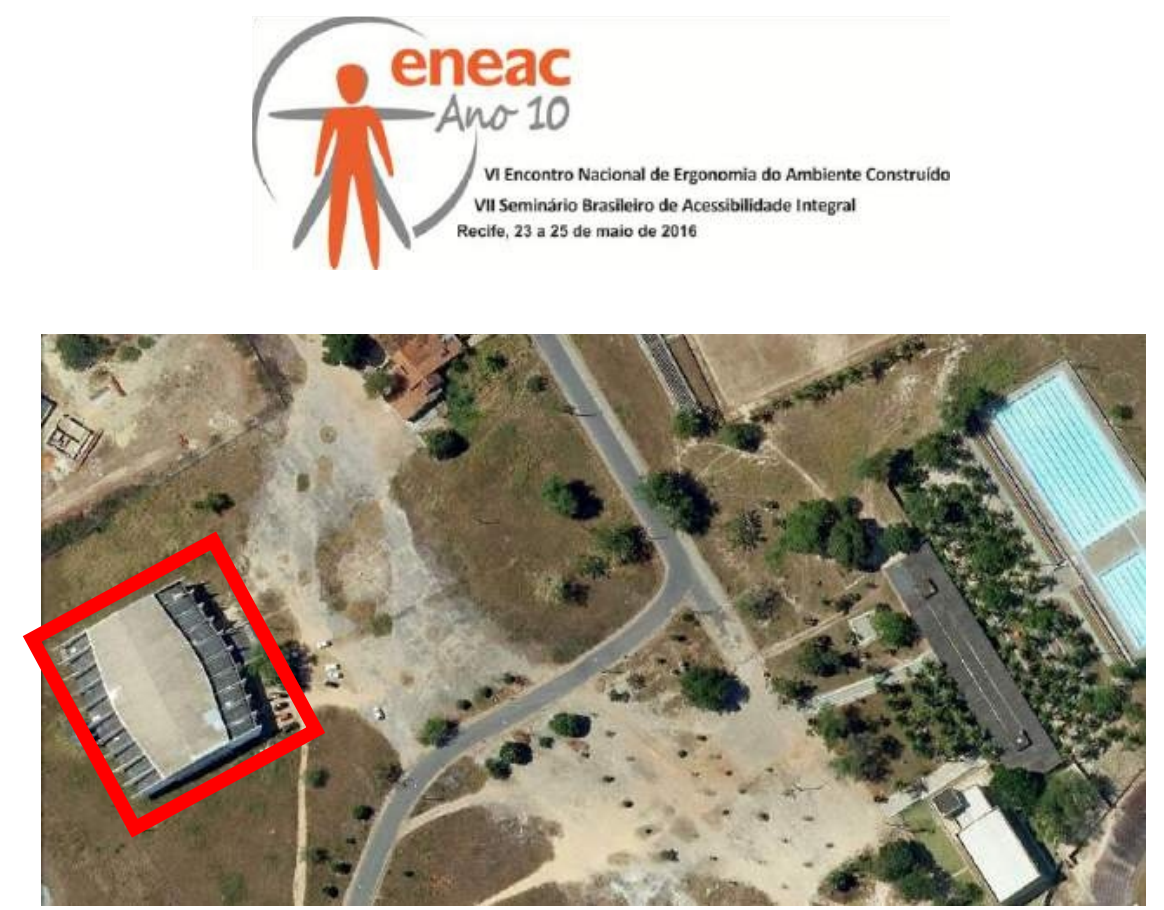

Fonte: Acervo pessoal (2013).

Figura 11 - Acesso ao ginásio

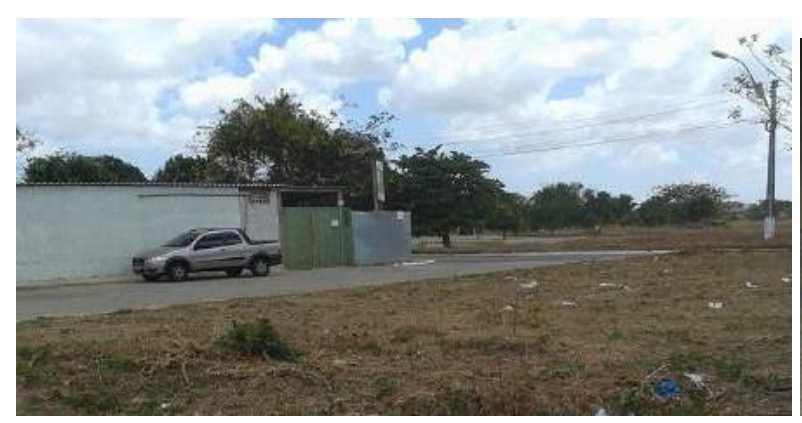

Fonte: Acervo pessoal (2013).
Figura 12 - Rampa de acesso ao ginásio

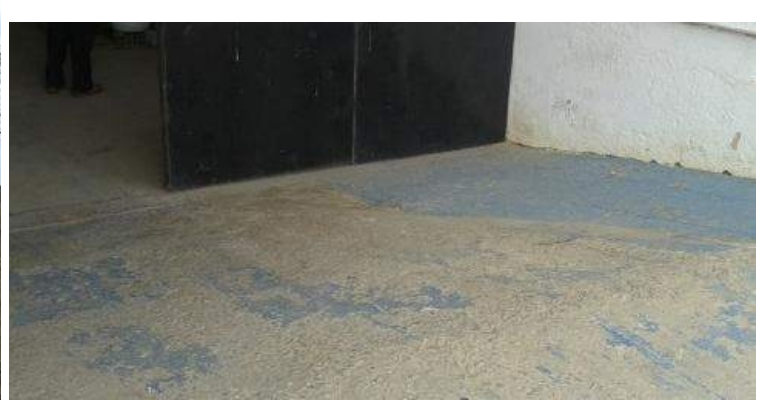

Fonte: Acervo pessoal (2013).

O ginásio não possui arquibancada acessível, além de degraus, não há outro elemento de circulação vertical que possibilite o acesso (vide figura 13). Contrariando, portanto, as indicações do Decreto 5.296/2004, que regula a exigência da reserva de $2 \%$ do total de assentos em locais públicos de aglomeração, tais como auditórios, teatros, para usuários de cadeira de rodas, pessoas com mobilidade reduzida e obesos.

Figura 13 - Quadra e arquibancadas do ginásio

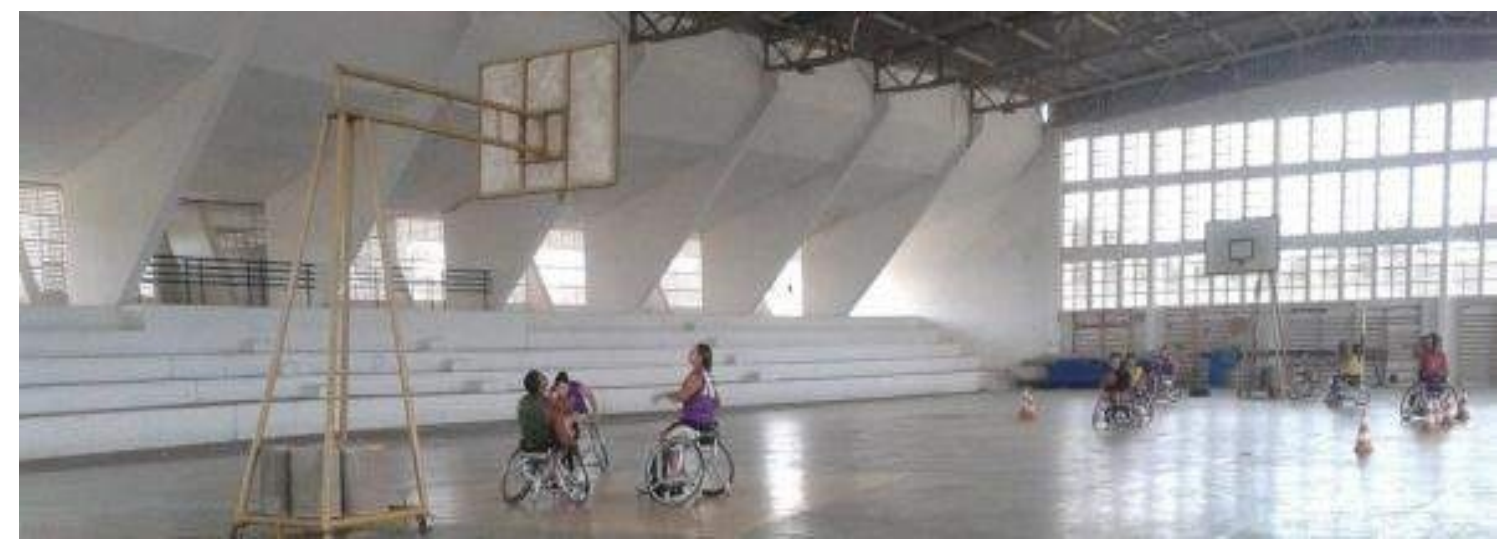

Fonte: Acervo pessoal (2013). 


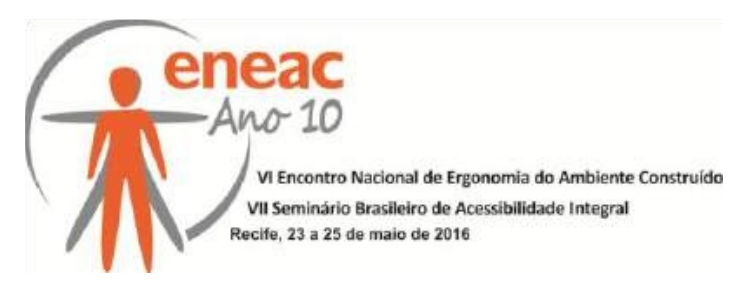

A área de banheiros e vestiários é semienterrada, em nível inferior ao nível da quadra. 0 acesso se dá de duas maneiras: por escada, desprovida de corrimão; ou por rampa, esta com inclinação acima da recomendada por norma. O banheiro do ginásio também apresenta elementos em desacordo com a norma. O Box, aparentemente acessível, não possui todas as barras de apoio indicadas, como também banco, nem área de transferência para área do chuveiro. Na bancada da pia, foi contemplada área de aproximação em altura adequada e espelho, porém, a torneira é de rosqueio e não do tipo alavanca (vide figura 14).

\section{Figura 14 - Acesso aos banheiros e vestiários do ginásio}
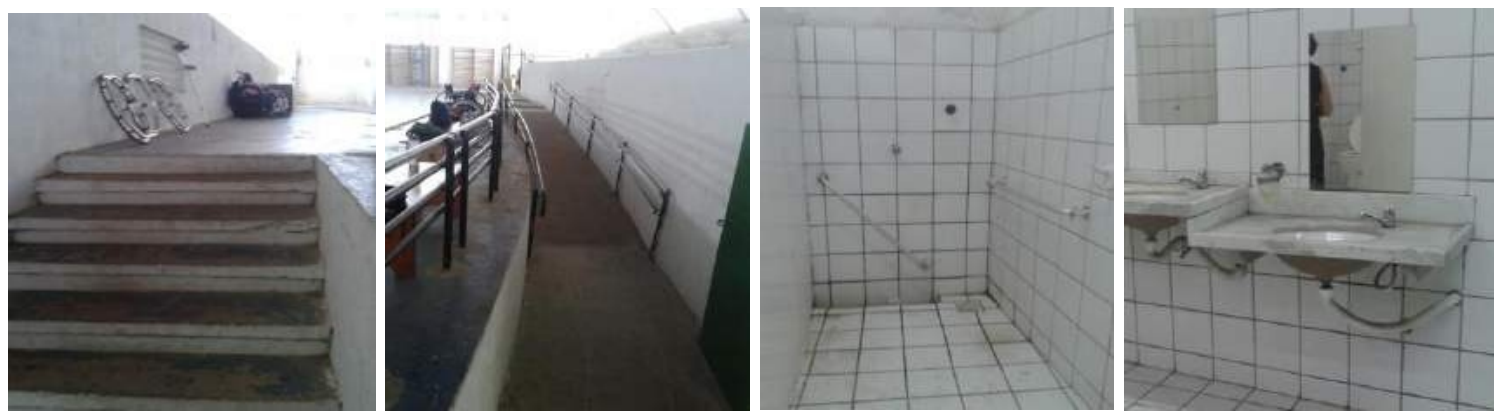

Fonte: Acervo pessoal (2013).

Pode-se afirmar que na reforma que ocorreu no ginásio coberto foram executados alguns requisitos de acessibilidade, como rampas, barras de apoio, bancada em altura diferenciada, mas a qualidade do serviço fica comprometida por deixar de lado aspectos importantes dos detalhes, como inclinação correta de rampa, corrimão e sinalização na escada, torneira do tipo alavanca, enfim, são detalhes que fazem a diferença.

\section{CONSIDERAÇÕES FINAIS}

Muitos foram os avanços no âmbito da acessibilidade e programas de inclusão social conquistados nas últimas décadas, dentre os quais destacamos as normas e decretos nacionais nesta década. Em escala local, faz-se necessário reconhecer os esforços neste sentido, como a elaboração do Guia de Acessibilidade Ceará (2009), desenvolvido pelo Governo do Estado em parceria com a Universidade Federal do Ceará, outras iniciativas dentro da própria universidade, através da criação da Secretaria de Acessibilidade no ano de 2010, em fazer repercutir o tema da acessibilidade em programas e no espaço físico da instituição. Apesar do mérito das ações positivas promovidas nos últimos anos, ainda existem muitos entraves à acessibilidade espacial e plena.

Por meio da APO realizada no IEFES, verificou-se que, apesar da necessidade de inclusão demandada pela natureza das atividades acadêmicas e esportivas desenvolvidas no complexo, bem como por iniciativas da UFC em promover a inclusão e a acessibilidade ampla, o espaço analisado não proporciona acessibilidade física plena a que se propõe. Em vários itens analisados, se constata a possibilidade de deslocamento de pessoas em cadeira de rodas ou pessoas com deficiência visual, mas com a ajuda de acompanhantes, a autonomia do usuário não está garantida.

Além das barreiras identificadas pelos desníveis, rampas de inclinações excessivas ou pavimentações inadequadas, fato que revela a ausência de uma visão de projeto sistêmico na articulação entre as diversas edificações, o desenho de mobiliários, a escolha e instalação de equipamentos, apontam para uma ausência de comprometimento com a 


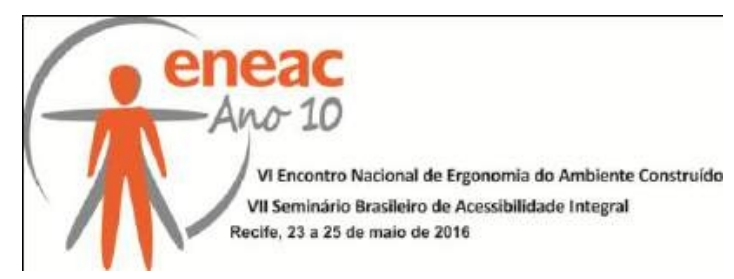

inclusão, materializada na inadequação do espaço e nas escolhas de especificação dos acabamentos de maneira não funcional.

Espera-se que, com a continuidade desses esforços, bem como outras ações de conscientização, sensibilização e formação, dentre as quais a inclusão da disciplina de Desenho Universal no currículo do curso de Graduação e Mestrado de Arquitetura e Urbanismo na UFC, a continuidade das ações da Secretaria de Acessibilidade da UFC, dentre outros, venham contribuir para que o cenário nas instituições públicas de ensino superior possa vir a ser mais positivo no futuro.

\section{REFERÊNCIAS}

ASSOCIAÇÃO BRASILEIRA DE NORMAS TÉCNICAS. NBR 9050: Acessibilidade a edificações, mobiliário, espaços e equipamentos urbanos. Rio de Janeiro, 2004.

BRASIL. Decreto $N^{\circ}$ 5.296, de 2 de dezembro de 2004, que regulamenta as Leis $n^{\circ} \mathrm{s} 10.048$, de 8 de novembro de 2000, que dá prioridade de atendimento às pessoas que especifica, e 10.098, de 19 de dezembro de 2000, que estabelece normas gerais e critérios básicos para a promoção da acessibilidade das pessoas com deficiência ou com mobilidade reduzida, e dá outras providências.

CAMBIAGHI, Silvana. Desenho universal: métodos e técnicas para arquitetos e urbanistas. São Paulo: Editora Senac São Paulo, 2007.

CEARÁ. Guia de Acessibilidade: Espaço Público e Edificações. 1 ed./ Elaboração: Nadja G.S. Dutra Montenegro; Zilsa Maria Pinto Santiago e Valdemice Costa de Sousa. Fortaleza: SEINFRA-CE, 2009.

IBGE, Censo Demográfico 2010. Disponível em: <http://www.ibge.censo2010.gov.br> Acesso em: 18/06/2013.

ORNSTEIN, Sheila; ROMÉRO, Marcelo. Avaliação Pós-Ocupação (APO) do ambiente construído. São Paulo: Studio Nobel; Editora da Universidade de São Paulo, 1992.

PREISER, Wolfgang F.E. Post-occupancy evaluation. New York: Van Nostrand Reinhold, 1988. 